antibitoic treatment can be evaluated. Early initiation of maternal antibiotic therapy is associated with shorther durations of hospital stay for newborns. Close follow-up of mothers with high risk pregnancies and extension of treatment duration are critical for determining prognosis in newborn infants.

\section{QUANDRY OVER THE USE OF ANTIFUNGAL PROPHYLAXIS IN PRETERM INFANTS: SURVEY OF CURRENT PRACTICE IN THE UNITED KINGDOM}

doi:10.1136/archdischild-2012-302724.1161

${ }^{1} \mathrm{~K}$ Durairaj, ${ }^{2} \mathrm{~V}$ Viswanath, ${ }^{1} \mathrm{M}$ Dyke. ${ }^{1}$ Neonatal Medicine, Norfolk and Norwich University Hospital, Norwich; ' ${ }^{2}$ Neonatal Medicine, Luton \& Dunstable University Hospital, Luton, UK

Introduction Prophylactic anti fungal use reduces the incidence of colonisation and invasive fungal infection in premature neonates. We surveyed the current regimens for the use of antifungal prophylaxis in the tertiary neonatal units across the UK.

Method We enquired about indications for use, drug of choice for prophylaxis, criteria for stopping the prophylaxis and drug used for suspected or proven fungal infection.

Results Out of 52 units 42 [81\%] responded. 7 units [17\%] did not use any prophylaxis. 26 units [62\%] had guidelines on the use of anti fungal prophylaxis. 9 units [21\%] used prophylaxis but did not have any guidelines. Of the units using prophylaxis, $43 \%$ used birth weight as a criterion ranging from $<750$ grams to $<1.2 \mathrm{kilogram}$. $51 \%$ of units used gestation as a criterion ranging from $<25$ weeks to $<32$ weeks. $20 \%$ of units used antibiotic use as their only criterion for starting prophylaxis. $31 \%$ used presence of longline as a criterion. Small number of units used abdominal surgery, prolonged intubation, NEC, Candida colonisation, postnatal steroids and ranitidine as a criterion. The commonest drug used for prophylaxis was fluconazole [50\%]. $29 \%$ of units used nystatin and $12 \%$ of units used miconazole gel. $26 \%$ of units used the same prophylactic drug when treating suspected or proven fungal infection.

Conclusion Despite evidence of the efficacy of anti-fungal prophylaxis, $17 \%$ of tertiary units are not using antifungal prophylaxis for infants at high risk. There remains considerable heterogeneity in indications and the specific antifungal used for prophylaxis.

\section{COMPARATIVE ANALYSIS OF STAPHYLOCOCCUS EPIDERMIDIS STRAINS ISOLATED FROM NEWBORNS}

doi:10.1136/archdischild-2012-302724.1162

${ }^{1} \mathrm{E}$ Hell, ${ }^{2} \mathrm{CG}$ Giske, ${ }^{1} \mathrm{~K}$ Gemzell Danielsson, ${ }^{3} \mathrm{G}$ Marchini. ${ }^{1}$ Dept. of Women's and Children's Health, Obstetrics and Gynecology Unit; ${ }^{2}$ Dept. of Microbiology, Tumor- and Cell Biology; ${ }^{3}$ Dept. of Women's and Children's Health, Neonatal Unit, Karolinska Institutet, Karolinska University Hospital, Stockholm, Sweden

Staphylococcus epidermidis are important opportunistic biofilm forming pathogens, particularly causing infection in patients with indwelling medical devices. Preterm infants represent a high-risk group for device-related $S$. epidermidis infections since they require the delivery of nutrients and drugs over long periods.

The present study compared genetic and phenotypic characteristics of $S$. epidermidis strains isolated from blood stream infections of preterm infants $(n=10)$ versus skin isolates obtained from healthy newborns $(n=16)$. Two reference strains were also included the study. Insertion element IS256, as a marker for invasiveness, was analysed by PCR. Antimicrobial susceptibility was testing against cefoxitin, gentamicin and vancomycin. Pulsed-Field Gel Electrophoresis was performed to study clonal relationship among strains.

$90 \%$ of the blood isolates were resistant to cefoxitin and gentamicin and all these carried IS256. All skin isolates were susceptible to both cefoxitin and gentamicin and all lacked IS256. All of the 28 strains included in the study were susceptible to vancomycin.
We conclude that the $S$. epidermidis strains isolated from blood stream infection in preterm infants are clonally not related to the normal colonizing $S$. epidermidis skin flora at birth, have different phenotypic features related to antimicrobial susceptibility, and have most probably originated from the hospital environment.

\section{EPIDEMIOLOGY OF PROVEN NOSOCOMIAL SEPSIS IN LOW BIRTH WEIGHT INFANTS ADMITTED IN THE LEVEL 3 NEONATAL INTENSIVE CARE UNIT}

doi:10.1136/archdischild-2012-302724.1163

M González, C Gómez, MG Espinosa, M Rodriguez, R Santos, E Salguero. Neonatal Intensive Care Unit, Hospital Carlos Haya, Málaga, Spain

Background Nosocomial infections remains a leading cause of morbidity and mortality in Neonatal Intensive Care Unit(NICU).

Aim To assess incidence, etiology and outcome of culture-proven nosocomial sepsis in low birth weight(LBW) infants.

Methods Retrospective study of preterm infants with birth weight $<1500 \mathrm{~g}$ and proven nosocomial sepsis admitted in NICU of Hospital Carlos Haya during 2011.

Results Sixty neonates experienced at least one or more episode of nosocomial sepsis out 160 LBW infants meaning an incidence of $37.5 \%$. $61 \%$ positive blood culture. Table one. Mortality was $6.6 \%$ of all patient with proven sepsis and $4 \%$ of all positive blood culture. In our series fungal sepsis were the most aggressive being responsible of the $50 \%$ of deaths.

Abstract 1163 Table 1 Etiology of nosocomial infections during 2011

\begin{tabular}{|c|c|c|}
\hline Gram Positives & $\begin{array}{l}\text { Coagulase negative Staphyloccocal } \\
\text { (including S.epidermidis) }\end{array}$ & $\begin{array}{l}67 \%(38 \% \\
\text { S.epidermidis })\end{array}$ \\
\hline & Enterococcus spp & $7 \%$ \\
\hline & S.aureus & $1 \%$ \\
\hline \multirow[t]{6}{*}{ Gram negatives } & Klebsiella penumomiae & $7 \%$ \\
\hline & Serratia marcescens & $5 \%$ \\
\hline & E.coli & $1 \%$ \\
\hline & Enterobacter spp & $4 \%$ \\
\hline & Psudomona spp & $5 \%$ \\
\hline & Other gram negatives & $1 \%$ \\
\hline Fungal & Candida spp & $2 \%$ \\
\hline
\end{tabular}

Conclusions Overall infections rate is similar to the current reports for level 3 hospitals. Gram positives organisms were common being S. epidermidis the most frequent. Related to gram negative K. pneumoniae, S. marcensces and Enterobacter were the most frequently isolateded. No cases of expanded spectrum of betalactamases bacterial. Mortality is less than previously reported.

\section{REDUCTION IN FUNGAL SYSTEMIC INFECTIONS IN PRETERM NEONATES WITH NYSTATIN PROPHYLAXIS}

doi:10.1136/archdischild-2012-302724.1164

MA Ihsan, M Yar, F Sabbagh, M Abu-ouf, MM Abou Al-Seoud. Neonatal DivisionPaediatric Department, King Fahad Armed Forces Hospital, Jeddah, Saudi Arabia

Background Invasive fungal infection is an important cause of mortality and morbidity in the very low birth weight (VLBW) and the extremely low birth weight (ELBW) infants. A policy of oral nystatin prophylaxis was introduced with the aim of reducing the incidence of invasive fungaemia among high risk neonates.

Aim To determine whether this policy had reduced the rates of invasive fungal infection.

Methods In December 2004 oral nystatin prophylaxis implemented for babies with birth weight equal or < than 1250 grams starting on $3^{\text {rd }}$ day of life till they retain their birth weight. In 2010 